\title{
Comparative Evaluation Of Two Techniques Of Sex Determination In Lovebirds (Agapornis Spp.)
}

\author{
Maria-Carmen TURCU ${ }^{1 *}$, Lucia-Victoria BEL ${ }^{1}$, Tommaso COLLARILE ${ }^{2}$ and Dana Liana PUSTA ${ }^{1}$ \\ ${ }^{1}$ Faculty of Veterinary Medicine, University of Agricultural Sciences and Veterinary Medicine Cluj-Napoca, Romania \\ ${ }^{2}$ Clinica per animali esotici, CVS, Roma, Italia \\ *corresponding author: carmen.turcu1603@gmail.com
}

Bulletin UASVM Veterinary Medicine 77(2)/2020

Print ISSN 1843-5270; Electronic ISSN 1843-5378

doi:10.15835/buasvmcn-vm:2020.0030

\begin{abstract}
Most lovebirds (Agapornis spp.) have no distinct sexual dimorphic traits. The objective of the paper was to compare the results of two sexing methods, surgical sexing by celioscopy and DNA sexing by PCR from blood samples, in order to evaluate their effectiveness. Materials used to carry out the studies were a $2.7 \mathrm{~mm}$ telescope and endoscopy unit, surgical instruments and DNA sampling kits provided by Exomed.cz laboratory. Forty-two lovebirds were included in this study. The endoscopic sexing procedure was performed by the method described by Divers. Blood sampling for DNA testing by PCR method was performed from the metatarsal vein. The results were different in the case of one lovebird, endoscopic sexing revealed it as male, compared to DNA testing, where it was identified as female. DNA sexing is a non-invasive method that might be more accurate than celioscopy in this species, and bird owners have easier access to it.
\end{abstract}

Keywords: Agapornis spp., celioscopy, DNA sexing, lovebird, PCR

\section{Introduction}

Most lovebirds (Agapornis spp.) do not show sexual dimorphism. Out of the nine species of lovebirds, only three show sexual dimorphism (Forshaw, 2010).

The lovebirds that do not show sexual dimophism are the peach-colored lovebird (Agapornis roseicollis), Fischer's lovebird (Agapornis fischeri), the masked lovebird or the yellow-collared lovebird (Agapornis personatus), the black-collared lovebird or the Swindern lovebird (Agapornis swindernianus), the Liliana lovebird or the Nyasa lovebird (Agapornis lilianae) and the black-cheeked lovebird (Agapornis nigrigenis) (Kuchinski, 1995).

The three species of lovebirds that display sexual dimorphism are the red-faced lovebird (Agapornis pullarius), the black-winged lovebird or the Abyssinian lovebird (Agapornis taranta) and the gray-faced lovebird or the Madagascar lovebird (Agapornis canus). The red-faced lovebird (Agapornis pullarius) is probably the least bred species of love parrot. It is considered a small lovebird, reaching a body weight of about 37 grams. The male has the inner face of the wings colored black and the head bright red, brighter than the female. The black-winged lovebird or the Abyssinian lovebird (Agapornis taranta) is usually found at higher altitudes. It is considered a large size lovebird, and can reach a body weight of about 50 grams. Males have black feathers on the inner face of their wings and a red forehead, and females are completely green. The Madagascar lovebird (Agapornis canus) is the only lovebird found on the island of Madagascar and is considered the most primitive of the genus Agapornis. It is considered the smallest lovebird, weighting arround 30 grams. The male has gray feathers on his head and the female is completely green (Kuchinski, 1995). 
The determination of sex in parrots can be obtained by several methods, some being more accurate than others. These are represented by traditional methods, surgical methods, genetic methods, hormonal methods for determining steroid hormones and ultrasound methods of the genital tract (O'Malley, 2005; Stanford, 2010).

Traditional methods of sexing birds involve observing the secondary sexual characteristics of the species, cloacal inspection, vent sexing (determining the width of the pubic arch), the size of the bird, the shape of the bird's head and behavior studies (O'Malley, 2005).

Genetic methods used for sexing birds involve, on the one hand, cytogenetic tests to highlight chromosomes by karyotyping (Fridolfsson and Ellegren, 1999), and on the other hand, modern molecular genetic tests that determine the sex of birds by DNA testing (Vučićević et al., 2012). Another method of early genetic sexing of birds is autosexing of day-old chicks (Pusta, 2013).

Surgical methods of sexing birds involve visualizing the gonads following a laparotomy or laparoscopy under general anesthesia (O'Malley, 2005).

Determining the level of steroid hormones in bird feces is a method of sexing birds that is based on the levels of estrogen or testosterone found in the feces of birds. Fresh faecal samples are required to make this determination. Female feces have a higher estrogen/testosterone ratio than males and vice versa, males have a higher estrogen/ testosterone ratio than females (Bercovitz et al., 1978; Cerit and Avanus, 2007).

Genital ultrasound is a method of sexing birds that involves the identification of oviducts. Sex determination by ultrasound is performed using an ultrasound probe placed at the cloacal level of unanesthetized birds to identify the oviduct (Hildebrandt et al., 1995).

\section{Materials and methods}

Materials used to carry out the studies were Karl Storz Veterinary Endoscopy America Inc. laparoscopic equipment, light source, laparoscopy camera, display, $2.7 \mathrm{~mm}$ telescope, surgical instruments (15 blade, Pean forceps, scissors, sterile gauze and 5-0 polyfilament absorbable suture material) and DNA sampling kits provided by Exomed.cz laboratory.
Forty-two lovebirds were included in this study. The lovebirds were approximately 1 year old and were raised by the same breeder.

The methods of choice for sexing the 42 lovebirds were surgical sexing by celioscopy and DNA sexing by PCR from blood sample. The objective of the paper was to compare the results of the two sexing methods in order to evaluate their effectiveness.

Endoscopic method of bird sexing:

Endoscopic sexing of the 42 lovebirds was performed using the technique of celioscopy through the left lateral approach with the limb pulled cranially, as previously described by Divers in 2015. A pre-anesthetic consultation was necessary in order to declare the birds clinically healthy and not egg binding. The parrots were fasted for 1-2 hours prior to the procedure. Patients were inhalatory anesthetized using a semi-closed nonrebreathing circuit. Induction was made on mask with $5 \%$ isoflurane, and maintenance with $2 \%$ isoflurane. The anesthetized patient was placed in right lateral recumbency with the wings extended dorsally. The left limb was pulled cranially, while the right limb was maintained in a normal position. The area of interest (Fig. 1) was represented by a triangular shape delimited cranially by the last rib, caudally by the medial crural flexor muscle and ventral by the parallel that passes at the level of the sternum. Subsequently, the left flank area was prepared by plucking and antisepsis with chlorhexidine. An incision of the skin of about 2-3 $\mathrm{mm}$ was made caudal to the last rib and ventral of the medial crural flexor muscle. With the help of a curved Pean forceps, the abdominal muscles were punctured in order to penetrate into the caudal thoracic air sac. Through the orifice thus created, a $2.7 \mathrm{~mm}$ telescope was inserted perpendicularly, penetrating the caudal thoracic air sac. Penetration into the caudal thoracic air sac is confirmed by identifying the lung (central), cranial thoracic air sac (left), abdominal air sac (right), liver and proventriculus (ventral), ribs and intercostal muscles (dorsal). Subsequently, the telescope is oriented caudally. Penetration into the left abdominal air sac is achieved by perforating the membrane using the tip of the telescope. At this level, the kidney-gonad-adrenal gland triad is identified. The gonads are located at the cranial pole of the kidney. Sometimes the adrenal gland is covered by the sexually active testicle enlarged in 
volume (Divers, 2015). Lastly, the skin was sutured with polyfilament absorbable suture material. Postoperatively, the lovebirds recovered from anesthesia within minutes. Postoperative analgesia after endoscopy is recommended (Divers, 2015). Nonsteroidal anti-inflammatory drugs, such as meloxicam, were used in this case.

DNA testing by PCR method of bird sexing:

Birds have different sex chromosomes than mammals. Females are heterogametic and have ZW sex chromosomes, while males are homogametic and have ZZ sex chromosomes. DNA testing for bird sexing involves identifying the $\mathrm{W}$ (female) chromosome. The identification of the female chromosome is done by amplifying the CHD gene (chromo-helicase-DNA binding protein) found on the sex chromosomes of birds, using the technique of PCR (Polymerase Chain Reaction) followed by agarose gel electrophoresis (Fridolfsson and Ellegren, 1999). The agarose gel is examined using an UV trans illuminator (Fridolfsson and Ellegren, 1999; Prathipa and Karthickeyan, 2017). Corresponding to the genes of the sex chromosomes, the electrophoresis gel shows single bands in males (ZZ), whereas in females double bands (ZW) (Prathipa and Karthickeyan, 2017).

DNA sexing in birds can be performed from blood samples, feathers, eggshells or mouth swabs

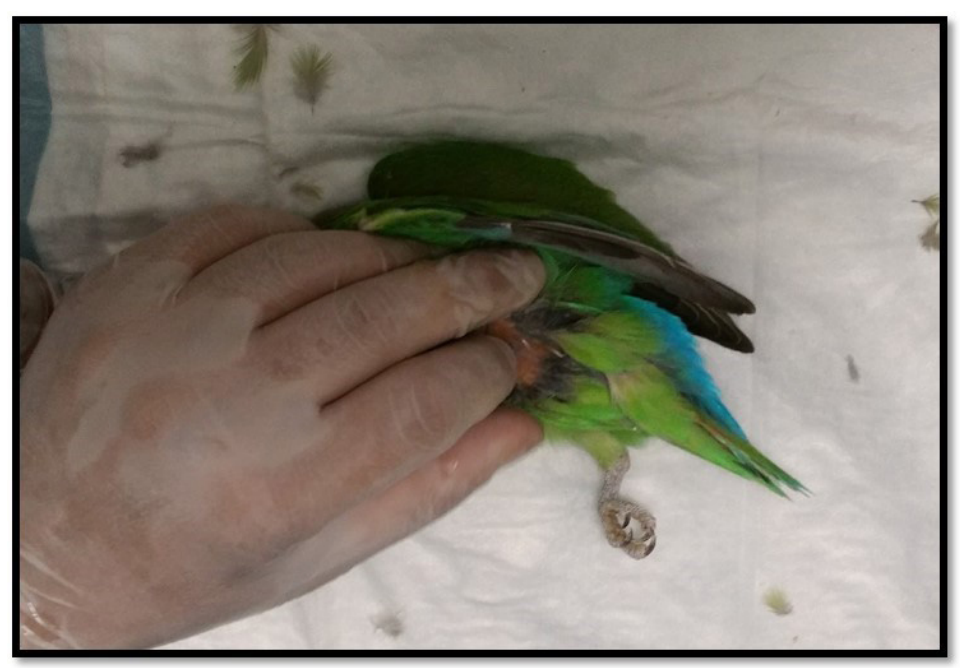

Figure 1. Patient positioning for endoscopic sexing

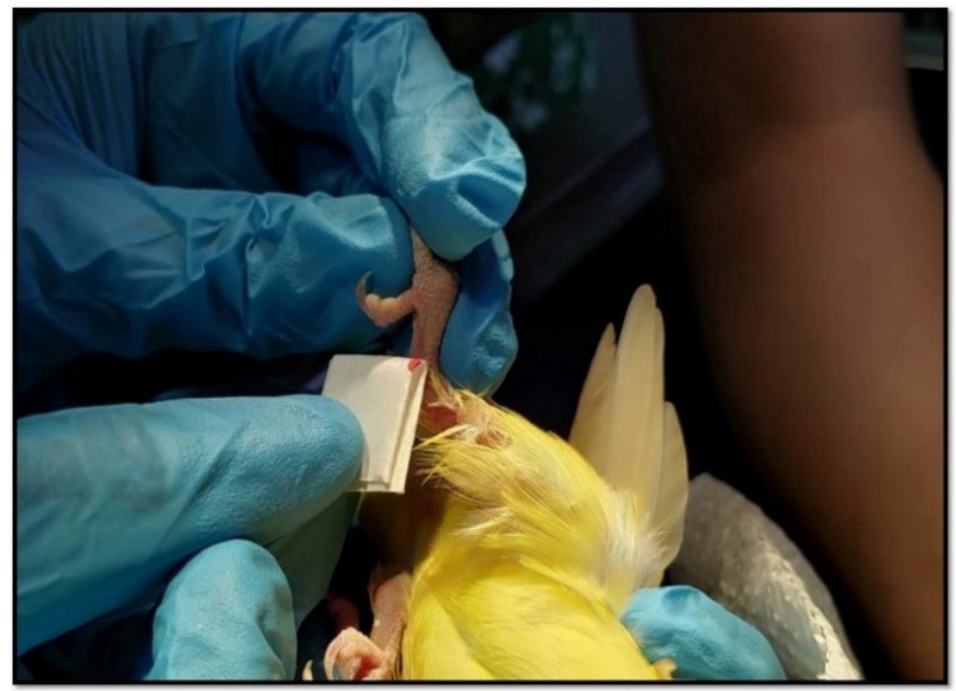

Figure 2. Blood sample taken for DNA sexing in Agapornis spp. 
(Prathipa and Karthickeyan, 2017, Mataragka et al., 2018). Feathers and oral swabs are easier to collect. Moreover, oral swabs are easier to process than feathers, whereas the easiest results to read are obtained from blood samples (Mataragka et al., 2018). DNA sexing in lovebirds (Agapornis spp.) can be performed from blood samples, feathers or mouth swabs (Prathipa and Karthickeyan, 2017). In our case, during anesthesia for endoscopy, blood samples were taken from the metatarsal vein of the 42 lovebirds (Fig. 2). PCR was performed using DNA testing kits provided by Exomed.cz.

DNA sexing in lovebirds involves the use of PCR technique followed by polyacrylamide gel electrophoresis (Prathipa and Karthickeyan, 2017). In the case of lovebirds, DNA isolation by PCRand amplification of the GHD gene is performed using the P2 (5'-TCTGCATCGCTAAATCCTTT-3 ') and P8 (5'-CTCCCAAGGATGAGRAAYTG-3') primer sets (Prathipa and Karthickeyan, 2017). The PCR reaction aims to amplify the DNA sequence containing the CHD1W gene using P2-P8 primers. Initially, the DNA is denatured at $94^{\circ} \mathrm{C}$ for 2 minutes, followed by a series of thermal reactions that gradually reduce the temperature by $1^{\circ} \mathrm{C}$ per cycle, starting at $60^{\circ} \mathrm{C}$ and reaching the temperature of $50^{\circ}$ C. Subsequently, another 25-35 additional cycles are run maintaining the temperature of $50^{\circ}$ C. After the last cycle, DNA extension is performed at $72^{\circ} \mathrm{C}$ for 5 minutes (Fridolfsson and Ellegren, 1999; Prathipa and Karthickeyan, 2017). Thus, the product obtained after PCR is separated by polyacrylamide gel electrophoresis and stained with ethidium bromide. The gel is examined using the UV trans illuminator (Fridolfsson and Ellegren, 1999; Prathipa and Karthickeyan, 2017). Regarding lovebirds, electrophoresis shows in males single bands, whereas in females double bands, corresponding to the genes of the sex chromosomes (Prathipa and Karthickeyan, 2017).

\section{Results and discussion}

Endoscopic sexing of the 42 lovebirds included in this study identified 26 males and 16 females. Celioscopy through the left lateral approach made visualization of the gonads possible. The testicles in male Agapornis spp. have an oval shape, are smooth and show obvious vascularity on their surface (Fig. 3). They are found at the cranial pole of the kidney, while identifying the kidney-gonadadrenal gland triad. The normal mature testicle of birds has an oval shape, is smooth and has obvious vascularity on the surface. Sometimes the congenital testicle on the right side can be observed through the transparency of the abdominal air sac In juvenile birds, the gonads are smaller and less differentiated. In general, in juvenile birds, the normal immature testis is smooth and has a sausage shape. The vas deferens with a sinuous "zig-zag" appearance can be traced from the gonad to the cloacal level (Divers, 2015).

The ovaries of Agapornis spp. females have follicles at various stages of development forming the shape of grapes (Fig. 4). The normal mature ovary of birds has the shape of grapes with follicles during various stages of development. In some species, the gonads may have partial or total physiological melanosis. Sexing by endoscopy

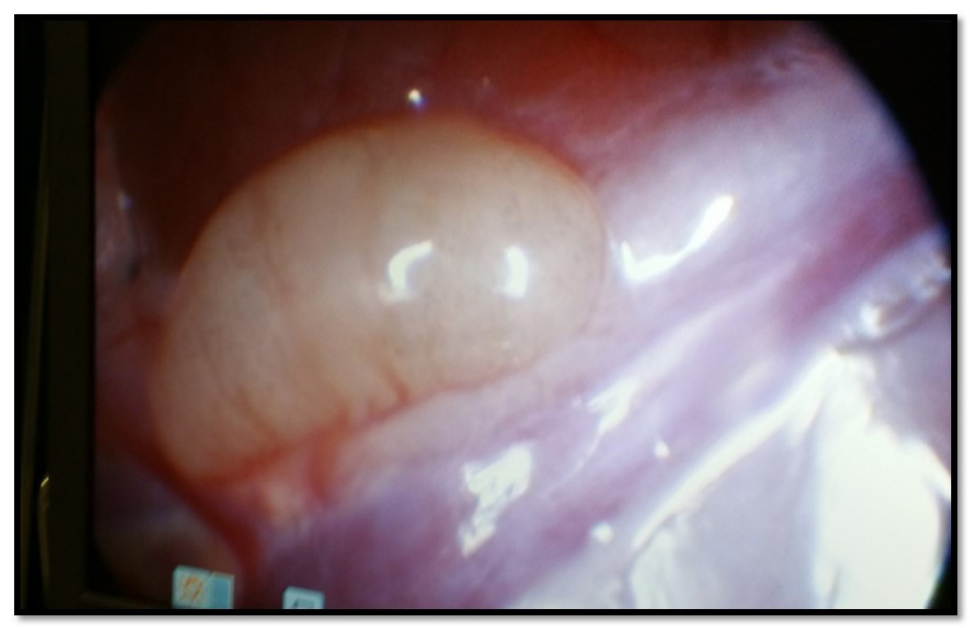

Figure 3. Mature testicle in Agapornis spp. 
does not present difficulties in adult female birds. In juveniles, however, the ovary is smaller and less differentiated. In general, in juvenile birds, the normal immature ovary has an irregular shape with grooves on its surface and poorly highlighted primary follicles. The twisted-looking oviduct can be traced from the gonad to the cloacal level (Divers, 2015).

The DNA sexing of the 42 lovebirds identified 25 males and 17 females by emphasizing the sex chromosomes, specifically the W (female) chromosome. One lovebird obtained different DNA results compared to endoscopic sexing. The results of DNA tests were released by the Exomed. cz laboratory (Fig. 5).

In 1984, Jones et al. performed 1056 endoscopes on 144 non-sexually dimorphic bird species of 15 orders. The purpose was to establish sex by direct inspection of the gonads. Anesthesia for endoscopy was considered dangerous in elderly and obese birds, where a mortality rate of up to $2 \%$ was found. Jones et al. (1984) stated at the time that celioscopy, although it involves surgery, is generally more practical and accurate than examining lymphocyte chromosomes or analyzing steroids in the feces.

In 1987, Prus and Schmutz compared surgical sexing using an otoscope with sexing by analyzing lymphocyte culture chromosomes on 22 psittacines belonging to eight different species. The comparison of the two techniques involved the following categories: success rate, quality of determination, cost, efficiency and risk. The conclusion of the study conducted by Prus and Schmutz in 1987 was that surgical sexing with an otoscope was preferred over sexing by examining chromosomes in lymphocyte culture in all categories except risk.

Subsequently, in 2001, Sae-Heng et al. sexed 21 lovebirds (Agapornis spp.) That already had sex, 12 males and 9 females. The study authors compared two methods of sexing Agapornis spp. The methods compared were the traditional one, vent sexing, and DNA testing by PCR. Following traditional sexing, 11 males and 10 females were identified, whereas by sexing by PCR, 12 males and 9 females. Sae-Heng et al. (2001) concluded that the accuracy of sexing by the PCR method was $100 \%$ compared to $76.19 \%$ for the method of determining the vent sexing in lovebirds. Cerit and Avanus performed poultry sex determinations in 2007. They stated that the identification of sex in poultry can be done by vent sexing, laparoscopy, determining steroid hormones and DNA testing. The preference for one of these methods also depends on the equipment of the laboratory and the experience of the examiners. The authors stated that vent sexing requires well-trained experts, and sometimes even professionals can misidentify the sex of birds. The same authors argued that laparoscopy is performed under general anesthesia and is a dangerous method that can be fatal to birds. In the 2000s, DNA sexing procedures required large amounts of blood and a few weeks to perform. Cerit and Avanus (2017) concluded that DNA-based techniques are more reliable than vent sexing, laparoscopy or determining steroid hormones.

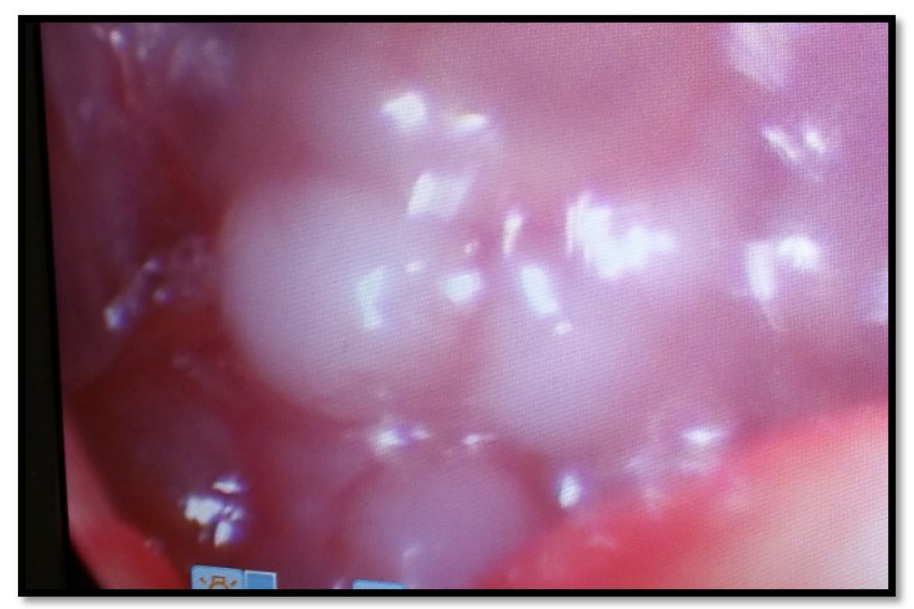

Figure 4. Mature ovary in Agapornis spp. 
In 2009, Hsu et al. compared endoscopic sexing with DNA sexing from blood samples of 20 Spilornis cheela hoya eagles. Initially Hsu et al sexed these eagles by endoscopy, and later the eagles were sexed by DNA. The study by Hsu et al concluded that the DNA test result in an eagle did not match the endoscopy result, but this was later proven to be caused by incorrect sex determination by the endoscopy technique. Hsu et al. (2009) concluded that determining the sex of eagles by DNA sexing method was as reliable as by laparoscopy method, noting that the latter might be influenced by age, season and body size of birds. In 2013, Wang et al. sexed 8 males and 8 females of Otus bakkamoena by two methods. The sex of these owls was initially determined by laparoscopy, and the data were then compared with the results obtained by the DNA sexing method. The results of the study by Wang et al. (2013) showed that molecular methods have a great potential in determining the sex of owls, although their accuracy remains to be tested on larger cohorts. Wang et al claim that DNA testing is a safe alternative to reduce the misdiagnosis of conventional sex by laparoscopy of birds.

In 2013, Morinha et al. studied DNA sexing by analyzing high-resolution melting (HRM), an advanced post-PCR method. The researchers applied this molecular sexing technique to a number of 14 species of birds, belonging to five orders and nine families. The samples collected were feathers, muscle tissue, blood and mouth swabs. For comparison, the sex of living individuals was identified by endoscopy, while the sex of dead birds was determined during the autopsy. Morinha

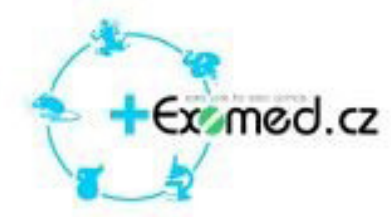

Protocol on sex determination in exotic bird (DNA analysis)

Protokol o analyze DNA za účelem určeni pohlaví

Owner: usamv Cluf

Majitel

Email: not given

Species: Rosy-faced lovebird

Drut ptaka

(Agapornis roseicalits)

Ring number / Chip number: ICDS 2723/N1643AAOE16

Gislo kroutku

Examined material: bloos

Wysectoni material: krev

Date of sample arrival: 13.02.2019

Datum daruteni vzorke

Sample code: 5403

Kod roovku

Result: female

W'sledek: samice

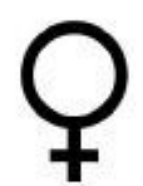

Date: 21.02.2019

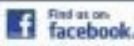

Datum

Eramed.co is not responsibic for the way of sampong and the arigin of the samples, Dut any for the resues obtained by analyses of the particular obtained material.

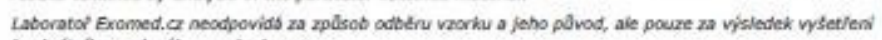
kanketeniho zastantho vzorku kve.

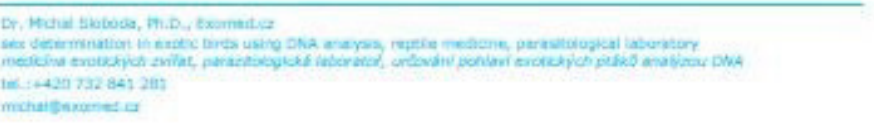

Figure 5. DNA test result 
et al. (2013) concluded that the accuracy of DNA sexing was $100 \%$. They stated that simplicity, speed, low cost and high sensitivity/specificity make this technique an excellent method for routine and large-scale sexing of birds.

Celioscopy is a minimally invasive surgical technique that has many advantages such as speed and accuracy in determining the sex of birds, lower risks than laparotomy, reduced surgical stress, respiratory function is less affected and postoperative anesthesia and hospitalization time are significantly reduced in comparison to celiotomy (Hernandez-Divers, 2005). Nevertheless, endoscopy also has disadvantages such as surgical risk, which, although minor, is still present (Greenacre and Gerhardt, 2016). A major disadvantage of celioscopy is the high cost of the equipment (Hernandez-Divers and HernandezDivers, 2004). Complications of celioscopy in birds are rare, as most birds undergoing endoscopic sexing are young and clinically healthy (Divers, 2015). Celioscopy is recommended only for clinically healthy patients, as it is not an emergency surgical procedure. This should be performed by an experienced veterinarian to minimize the risk of complications (Chavez and Echols, 2007). The most common complications of celioscopy are minor hemorrhages that occur most often due to lack of experience of the examiner. In rare cases, subcutaneous emphysema may occur postoperatively due to the strictly cutaneous suture, but it heals by itself within a few days if the bird is not subjected to effort. One method of preventing the occurrence of postoperative subcutaneous emphysema is to a suture both the skin and the abdominal muscles using absorbable sututre material. Massive intra-abdominal haemorrhages are considered major complications of celioscopy that can endanger the life of the animal, but which are very rare if the procedure is performed by an experienced veterinarian (Hernandez-Divers and Hernandez-Divers, 2004; Divers, 2015). Complications of celioscopy in birds are rare, as most birds undergoing sexing are young and clinically healthy (Divers, 2015). Celioscopy is recommended only for clinically healthy patients, as it is not an emergency surgical procedure. This should be performed by an experienced veterinarian to minimize the risk of complications (Chavez and Echols, 2007).There are few situations in which celioscopy has contraindications. These include patients at high risk of anesthesia, with intercurrent conditions such as obesity or various large, tumor-like masses that can compress or obliterate the air sacs and thus narrow the visual field of the laparoscopic camera. In birds with ascites or intra-abdominal hemorrhage, the left or right lateral approach is not recommended because fluids will inevitably enter the air sacs. In such cases, the ventral approach on the midline is recommended, if it is absolutely necessary to perform an endoscopy. Other contraindications are represented by females during egg laying and major subcutaneous emphysema caused by perforation of the air sacs (Hernandez-Divers and Hernandez-Divers, 2004; Chai and Roman, 2005; Korbel, 2012).

Recent studies show that DNA sexing is preferred over celioscopy because DNA testing is a noninvasive method that has many advantages such as accuracy and precision in sexing, an economic advantage, given the low cost of laboratory analysis of samples, it is considered safer because samples do not endanger the lives of birds and do not put them at risk of infection, moreover feathers can be collected from the nest thus avoiding the stress of handling birds. Another advantage is that birds of all ages can be safely sexed, especially juveniles (Griffiths, 2000; Bermúdez-Humarán et al., 2002; Cerit and Avanus, 2007; Vučićević et al., 2012). The main disadvantages of DNA sexing are the equipment needed in order to perform it and the time it takes to issue the results, in comparison with endoscopic sexing, where the result is obtained on the spot (Griffiths, 2000). Due to its many advantages, the most important being its accuracy of almost $100 \%$, genetic sex has many applications in behavioral medicine, conservative medicine, wild bird management, breeding of different species of birds, improving the breeding programs of birds in captivity, in the analysis of poultry reproduction strategies, in evolutionary studies or in forensic medicine (Morinha et al., 2012).

\section{Conclusions}

Lovebirds (Agapornis spp.) present 9 breeds, but only three of them show sexual dimorphism. Moreover, crossbreeding makes it even more difficult to sex lovebirds by their phenotypic characters. 
Traditional methods of sexing birds have low accuracy and are considered rather empirical. The only traditional method with $100 \%$ accuracy is egg binding in females, but it has the disadvantage of being belated.

In determining the steroids in bird droppings, erroneous results may occur due to seasonal variations and the age of the birds, especially outside the mating season. The most reliable results are obtained from adult birds during the mating season. Measuring steroids is a time consuming procedure. Because steroid levels vary, sex cannot be accurately identified by this technique.

Ultrasound of the genital tract has the advantage of being atraumatic and the disadvantage of requiring an experienced examiner. This technique is not an applicable technique for sexing parrots due to their small size.

Laparoscopic sexing requires special equipment and experience from the examiner. Laparoscopic sexing can be influenced by season, age and body size of birds. The testicles in male Agapornis spp. have an oval shape, are smooth and show obvious vascularity on their surface. The ovary of Agapornis spp. females has follicles at various stages of development forming the shape of grapes. No complications were observed after performing the endoscopic sexing of the 42 lovebirds.

Molecular DNA sexing methods allows reliable, rapid and economical determination of sex in most bird species. Moreover, bird owners have easier access to it.

In the past surgical sexing of birds was preferred. Nowadays, after genetic sexing techniques developed, DNA sexing is considered to have $100 \%$ accuracy, simplicity, speed, low cost, high sensitivity/specificity and is considered a safe alternative to reduce the misdiagnosis of laparoscopic sexing in birds.

In the present study one lovebird obtained different results at endoscopic sexing, where it was identified as male, compared to DNA testing, where it was identified as female. This is considered to be a consequence of human error. Given that the lovebirds had not yet reached sexual maturity and their ovaries were in various stages of development, there is a possibility that the examiner may have confused the immature ovary with the testicle during endoscopy. Moreover, mixing of the blood samples for DNA sexing could not be excluded.

In conclusion, DNA sexing is a non-invasive method that might be more accurate than celioscopy in this species.

Acknowledgments. This research did not receive any specific grant from funding agencies in the public, commercial, or not-for-profit sectors.

\section{References}

1. Bercovitz AB, Czekala NM, Lasley BL (1978). A new method of sex determination in monomorphic birds. The journal of Zoo Animal medicine, 9(4):114-124.

2. Bermúdez-Humarán LG, García-García A, Leal-Garza CH, Riojas-Valdes VM, Jaramillo-Rangel G, Montes-deOca-Luna R (2002). Molecular sexing of monomorphic endangered Ara birds. Journal of Experimental Zoology, 292(7):677-680.

3. Cerit H, Avanus K (2007). Sex identification in avian species using DNA typing methods. World's Poultry Science Journal, 63(1):91-100.

4. Chai N, Roman Y (2005). L'endoscopie invasive et noninvasive. Le Point Vétérinaire, 253(3):2-9.

5. Chavez W, Echols MS (2007) Bandaging, endoscopy, and surgery in the emergency avian patient. Veterinary Clinics of North America: Exotic Animal Practice, 10(2):419-436.

6. Divers SJ (2015). Endoscopic sex identification in chelonians and birds (Psittacines, Passerines, and Raptors). Veterinary Clinics: Exotic Animal Practice, 18(3):541-554.

7. Forshaw JM (2010). Parrots of the World (Vol. 70) Princeton University Press., pg. 154-159.

8. Fridolfsson AK, Ellegren H (1999). A simple and universal method for molecular sexing of non-ratite birds. Journal of avian biology, 116-121.

9. Greenacre CB, Gerhardt L (2016). Psittacine and Passerine Birds. Exotic Animal Medicine for the Veterinary Technician, pg. 90

10. Griffiths R. (2000). Sex identification in birds. In Seminars in avian and exotic pet medicine (Vol. 9, No. 1, pp. 14-26). WB Saunders.

11. Hernandez-Divers SJ (2005). Minimally invasive endoscopic surgery of birds. Journal of Avian Medicine and Surgery, 19(2):107-121.

12. Hernandez-Divers SJ, Hernandez-Divers SM (2004). Avian diagnostic endoscopy. Compendium on continuing education for the practicing veterinarian.

13. Hildebrandt T, Pitra C, Sömmer P, Pinkowski M (1995). Sex identification in birds of prey by ultrasonography. Journal of Zoo and Wildlife Medicine, 367-376.

14. Hsu HA, Wang PH, Chao MC, Chan FT, Wang LM, Lin PI, Ding ST (2009). Use of random amplified polymorphic DNA to identify several novel markers for sex identification 
in the crested serpent eagle and crested goshawk. Theriogenology, 72(6):755-764.

15. Jones DM, Samour JH, Knight JA, Ffinch JM (1984). Sex determination of monomorphic birds by fibreoptic endoscopy. The Veterinary Record, 115(23):596-598.

16. Korbel R (2012). Avian Endoscopy-Principles and Application. Proceedings of AAVAC/UEPV Conference Melbourne

17. Kuchinski K (1995). African Lovebirds Genus Agapornis. AFA Watchbird, 22(4):4-7.

18. Mataragka A, Balaskas C, Sotirakoglou K, Ikonomopoulos ] (2018). Comparative evaluation of the performance of the PCR assays commonly used for the determination of sex in avian species. Journal of King Saud University-Science, 32(1):228-234.

19. Morinha F, Cabral JA, Bastos E (2012). Molecular sexing of birds: A comparative review of polymerase chain reaction (PCR)-based methods. Theriogenology, 78(4):703-714.

20. Prathipa G, Karthickeyan SMK (2017). Sex Determination in African Love Birds (Agapornis Sp.) Using P2/P8 set of Primers by PCR, Indian Vet. J, 94(05):16-17.
21. Prus SE, Schmutz SM (1987). Comparative efficiency and accuracy of surgical and cytogenetic sexing in Psittacines. Avian diseases, 31(2):420-424.

22. Pusta DL (2013) Fundamental animal genetics (in Romanian), 2nd ed., Colecţia Veterinaria, pg. 56, pg. 60. and pg. 155-156.

23. Sae-Heng N, Somgird C, Kravapong D, Vinitchaikul P, Wataganara P, Tang-Munkhong P (2001). Bird sexing by polymerase chain reaction. Warasan Sattawaphaet.

24. Stanford M (2010). Cage and aviary birds. In BSAVA manual of exotic pets, pg. 167-187.

25. Vučićević M, Stevanović J, Vučićević I, Pantelić A, Đelić N, Resanović R, Stanimirović Z (2012). Sex determination in game birds management. In Int. Symp. Hunting, "Modern aspects of sustainable management of game population" Zemun-Belgrade (pg. 91-94).

26. Wang PH, Hsu HA, Chao MC, Chan FT, Wang LM, Lin PI, Ding ST (2013). Sex identification in the Collared Scops Owl (Otus bakkamoena) with novel markers generated by random amplified polymorphic DNA. Conservation genetics resources, 5(1):239-242. 